Gelanggang Pendidikan Jasmani Indonesia

\title{
VALIDASI EUROFIT TEST PADA SISWA SEKOLAH DASAR INDONESIA
}

\author{
Dona Sandy Yudasmara ${ }^{1 \square}$, Taufik ${ }^{2}$, Nurrul Riyad Fadhli ${ }^{3}$ \\ Universitas Negeri Malang \\ dona.sandy.fik@um.ac.id
}

\begin{tabular}{l}
\hline Info Artikel \\
\hline Sejarah Artikel: \\
Diterima: April-2020 \\
Disetujui: Mei-2020 \\
Dipublikasikan : Juni-2020 \\
\hline Kata Kunci: \\
eurofit test, siswa sekolah dasar \\
\hline
\end{tabular}

Abstrak

Tujuan penelitian ini adalah untuk mengembangkan model asesmen aktivitas jasmani anak sekolah dasar dan mengetahui tingkat aktivitas jasmani anak sekolah dasar. penelitian ini menggunakan langkah-langkah penelitian dan pengembangan yang disarankan Borg dan Gall (1983), dan dipadukan dengan langkah-langkah penyusunan tes keterampilan olahraga yang disarankan Scott dan French (1959) dengan pendekatan konseptual. Hasil nilai korelasi dan regresi linier diperoleh nilai validitas untuk siswa yang diantaranya; Bass Test dengan Plate taping untuk putri; 0,154, putra; 0,212; validitas Bass Test dan Shuttle Run untuk putri; 0,236, putra; 0,196 dan Validitas Plate Taping dan Shuttle Run untuk putri; 0,342, putra; 0,003. Koefisien Reliabilitas Bass Test untuk siswa putri; 0,591, putra 0,157. Koefisien Reliabilitas Plate Taping untuk siswa putri; 0,722, putra; 0,592. Koefisien Reliabilitas Plate Taping untuk siswa putri; 0,159, putra; 0,175. Dapat disimpulkan bahwa instrument Eurofit Test memiliki tingkat validitas dan reliabilitas yang sedang apabila digunakan pada konteks siswa sekolah dasar Indonesia.

Abstract

The aimed of this study was to validate of physical activity assessment of elementary school children and determine the level of physical activity of elementary school children using Eurofit Test. This study used the steps of research and development suggested by Borg and Gall (1983), and is integrated with sports skills preparation tests suggested by Scott and French (1959) with a conceptual approach. The results of the correlation value and linear regression obtained value of validity for students including; Bass Test with Plate taping for girls; 0,154, male; 0.212; the validity of the Bass Test and Shuttle Run for girls; 0,236, male; .196 and Plate Taping and Shuttle Run Validity for women; .342, male; 0.003 . Bass Test Reliability Coefficient for female students; 0.591 , son 0.157 . Plate Taping Reliability Coefficient for female students; 0.722 , male; 0.592 . Plate Taping Reliability Coefficient for female students; 0,159 , male; .175. It can be concluded that the Eurofit Test instrument has a moderate level of validity and reliability when used in Indonesian elementary school student's context.

(C) 2020 Universitas Negeri Malang 


\section{PENDAHULUAN}

Kegiatan pembelajaran pendidikan jasmani merupakan wadah bagi anak untuk mendorong pertumbuhan fisik, perkembangan psikis, keterampilan motorik, pengetahuan, penalaran, penghayatan nilai-nilai sportivitas, dan pembiasaan pola hidup sehat yang bermuara untuk merangsang pertumbuhan dan perkembangan kualitas fisik dan psikis yang berimbang. Pendidikan Jasmani dapat meningkatkan perilaku dalam kegiatan belajar terutama keterampilan-keterampilan yang terkait dengan saintifik (Álvarez-Bueno et al., 2017). Pada masa kanak-kanak akhir merupakan masa yang sangat tepat dalam mulai memberikan berbagai macam stimulus supaya anak dapat berkembang secara optimal. Aspek gerak dasar fundamental sangat penting untuk ditingkatkan untuk membantu kapasitas kesehatan dan akademik anak (Chomitz et al., 2009; Howie \& Pate, 2012; Jeon et al., 2016; Stephani et al., 2019; Zach et al., 2017). Maka diperlukan anak memerlukan kondisi sehat jasmani agar tahap-tahap perkembagan berjalan dengan baik (Aadland et al., 2017; Donnelly et al., 2016; Harvey et al., 2018). Kesehatan jasmani mutlak diperlukan anak, terlebih anak yang berada dalam usia sekolah dasar memasuki periode pertumbuhan dan perkembangan. Peningkatan kesegaran jasmani di lingkungan sekolah terutama sekolah dasar perlu dibina untuk menunjang tercapainya proses belajar yang optimal.

Agar bisa mengikuti pelajaran dan berkonsentrasi terhadap mata pelajaran, seorang siswa Sekolah Dasar tidak hanya perlu sehat, namun harus juga bugar/segar jasmaninya. Sehat pada umumnya dimaknai sebagai bebas dari penyakit, tetapi keadaan profil fisik yang prima merupakan indikasi anak sehat (Hills et al., 2011; Saint Albin et al., 2017; Sallis et al., 1997). Sehat dengan arti bebas dari penyakit belum tentu menjamin kemampuan anak untuk mampu bertahan dalam mengikuti pelajaran, berfikir, dan merespon terhadap pelajaran yang diterima di kelas atau pada saat belajar di rumah. Namun apabila siswa memiliki kebugaran jasmani yang dalam kategori kurang, dimungkinkan akan tidak mampu mengikuti/menerima beban pelajaran yang sebetulnya ini adalah tugas dari seorang siswa, serta anak tidak dapat beraktifitas sebagaimana mestinya.

Hasil penelitian terbaru mencatat pengguna internet di Indonesia yang berasal dari kalangan anak-anak dan remaja diprediksi mencapai 30 juta. Penelitian juga mencatat ada kesenjangan digital yang kuat antara anak dan remaja yang tinggal di perkotaan dengan yang tinggal di pedesaan. Studi ini menelusuri aktivitas online dari sampel anak dan remaja yang melibatkan 400 responden berusia 10 sampai 19 tahun di seluruh Indonesia dan mewakili wilayah perkotaan dan pedesaan. Sebanyak 98 persen dari anak dan remaja mengaku tahu tentang internet dan 79,5 persen di antaranya adalah pengguna internet. Dalam penelitian ini terdapat sekitar 20 persen/responden yang tidak menggunakan internet (Broto, 2014). Alasan utamanya adalah tidak memiliki perangkat atau infrastruktur untuk mengakses internet atau mereka dilarang oleh orang tua untuk mengakses internet. Terkait data tersebut di atas, aktifitas gerak anak di Indonesia berkurang dikarenakan adanya internet yang berada di genggaman tangan melalui smartphone mereka serta kebiasaan duduk menetap yang lama di depan layar tersebut. Berkurangnya aktifitas gerak akan mempengaruhi tingkat kebugaran fisik seseorang. Kualitas belajar siswa salah satunya dipengaruhi oleh tingkat kebugaran fisiknya (Haapala et al., 2017; M. Tremblay \& Lloyd, 2010; M. S. Tremblay et al., 2011).

Faktor yang mempengaruhi tingkat kebugaran jasmani siswa adalah umur, jenis kelamin, somatotipe, kondisi kesehatan, status gizi, berat badan, waktu istirahat serta aktifitas jasmaniah (Warburton et al., 2006). Dari pendapat tersebut dapat ditelaah aktifitas jasmaniah memegang peranan yang cukup penting terhadap status kebugaran jasmani seseorang (Mullender-Wijnsma et al., 2015; Venetsanou \& Kambas, 2010). Siswa pada era digital saat ini memiliki waktu aktifitas fisik lebih sedikit dari pada siswa pada era sebelumnya. Hal tersebut dikarenakan adanya beberapa faktor, mulai dari tuntutan akademik yang sangat tinggi serta maraknya media sosial yang menyebabkan tersitanya waktu untuk melakukan aktifitas fisik.

Secara pasti tingkat kesegaran jasmani hanya dapat diketahui melalui tes dan pengukuran yang dilakukan oleh setiap orang. Aktifitas jasmani merupakan aktifitas yang melibatkan keseluruhan bagian tubuh dan pengeluaran energi. pengukuran aktifitas tersebut berhubungan dengan frekuensi, durasi, intensitas dan jenis perilaku pada waktu tertentu, dilakukan dengan pengadministrasian data maupun dengan sensor gerak secara langsung, berlangsung dalam waktu tertentu maupun selamanya (Ainsworth et al., 2015; Craig et al., 2003). Untuk mengetahui dan menilai tingkat kesegaran jasmani seseorang dapat dilakukan dengan pengukuran performa gerak maupun kapasitas fisik. Identifikasi tes kesegaran jasmani secara umum dilakukan melalui asesmen lapangan (Lang et al., 2018; Mintah, 2003; Ruiz et al., 2011). Pengukuran kesegaran jasmani dilakukan dengan tes kesegaran jasmani. 
Untuk melakukan tes diperlukan adanya alat/instrumen. Asesmen lapangan tersebut akan dipengaruhi oleh karakteristik testee (peserta tes) terkait validitas hasil yang akan diperoleh.

\section{METODE}

Metode penelitian yang paling tepat digunakan dalam penelitian ini adalah metode penelitian dan pengembangan. Model penelitian dan pengembangan yang digunakan adalah model prosedural. Model prosedural adalah model yang bersifat deskriptif, yaitu menggariskan langkah-langkah yang harus diikuti dan dilakukan untuk menghasilkan produk. Dalam penelitian ini menggunakan langkahlangkah penelitian dan pengembangan yang disarankan (Gall, M. D., Gall, J. P., \& Borg, 2003, 2006), dan dipadukan dengan langkah-langkah penyusunan tes keterampilan olahraga yang disarankan (Ingleby, 2012).

Subjek penelitian terdiri dari (1) Siswa putra dan putri Sekolah Dasar tahun ajaran 2018/2019 kelas IV dan V : Jumlah subyek adalah 36 siswa putra, dan 38 siswa putri. Instrumen yang digunakan dalam penelitian ini adalah (1) kuesioner, (2) tes aktivitas jasmani, (3) pengamatan dan penilaian menggunakan rubrik pengamatan dan penilaian aktivitas jasmani, dan diskusi kelompok (focus group discussion). Kuesioner digunakan untuk mengumpulkan data tentang kebutuhan dibuatnya tes aktiitas jasmani dalam proses analisis kebutuhan. Tes digunakan untuk mengumpulkan data aktivitas jasmani menggunakan butir-butir tes eksperimen yang terdiri dari tes aktivitas jasmani. Rubrik pengamatan dan penilaian digunakan untuk mengumpulkan data kriterion pembanding. Data pengamatan dan penilaian dilakukan oleh para pakar pembelajaran evaluasi pendidikan jasmani dan guru pendidikan jasmani menggunakan skala penilaian (judge rating scale). Diskusi kelompok (focus group discussion) tim peneliti dan pengembangan dilakukan untuk menyempurnakan produk model asesmen aktivitas jasmani.

Teknik analisis data yang digunakan antara lain Teknik analisis kualitatif digunakan untuk menganalisis data hasil analisis kebutuhan, evaluasi ahli, dan hasil tes aktivitas jasmani. Data hasil analisis kebutuhan dianalisis menggunakan pendekatan kualitatif dengan cara mengidentifikasi dan mendeskripsikan data dalam bentuk kalimat-kalimat pernyataan tentang kebutuhan dibuatnya tes aktivitas jasmani untuk siswa putra dan putri Sekolah Dasar. Data hasil evaluasi ahli dianalisis dengan cara memaparkan pendapat dan masukan ahli pembelajaran dalam bentuk kalimat-kalimat pernyataan. Terutama saran dan masukan terhadap produk model asemen aktivitas jasmani yang dikembangkan dalam penelitian ini, untuk menyempurnakan produk yang dikembangkan. Diskusi kelompok (focus group discussion) tim peneliti dan pengembangan dilakukan untuk menyempurnakan produk model asesmen aktivitas jasmani untuk anak sekolah dasar. Teknik analisis statistik korelasi product moment digunakan untuk-memperoleh koefisien vailiditas setiap butir tes eskperimen, dan memperoleh reliabilitas setiap butir tes eksperimen. Koefisien validitas dilakukan dengan menghitung korelasi antara setiap butir tes eksperimen dengan kriterion. Koefisien korelasi antara setiap butir tes eksperimen dengan kriterion merupakan koefisien validitas butir tes eksperimen, yaitu tes aktivitas jasmani. Koefisien reliabilitas diperoleh dengan menggunakan teknik belah dua, yaitu mengkorelasikan antara jumlah hasil tes skor ganjil dan jumlah skor genap setiap butir tes eksperimen. Setelah diperoleh koefisien korelasi ganjil dan genap dilanjutkan analisis menggunakan rumus dari Spearman-Brown untuk memperoleh reliabilitas keseluruhan setiap butir tes, yaitu koefisien reliabilitas model asesmen aktivitas jasmani untuk anak sekolah dasar. . Teknik analisis korelasi yang digunakan adalah teknik analisis korelasi product moment dari Pearson. Teknik analisis korelasi product moment digunakan sebab data hasil tes adalah berskala interval.

\section{HASIL}

Sebelum melakukan pengolahan data. Data yang diperoleh akan dirubah terlebih dahulu menjadi data Tskor karena satuan data yang diperoleh dalam penelitian ini berbeda-beda. 
Tabel 1. Daftar Belanja Statistik Hasil Tes Kebugaran Jasmani Keseimbangan (X1), Koordinasi (X2) dan Kelincahan (X3) Siswa Sekolah Dasar

\begin{tabular}{|c|c|c|c|c|c|c|}
\hline Variabel & $\sum \mathbf{X}$ & $\sum \mathbf{X}^{2}$ & $\sum \mathrm{X} 1 \mathrm{X} 2$ & $\sum \mathrm{X} 1 \mathrm{X} 3$ & $\sum \mathrm{X} 2 \mathrm{X} 3$ & Mean \\
\hline \multicolumn{7}{|l|}{ Putra } \\
\hline Keseimbangan (X1) & 200 & 1280 & & & & 5,6 \\
\hline Koordinasi (X2) & 500,6 & 7044,447 & 700,560 & 673,499 & 974,059 & 13,9 \\
\hline Kelincahan (X3) & 473,5 & 6276,237 & & & & 13,153 \\
\hline \multicolumn{7}{|l|}{ Putri } \\
\hline Keseimbangan (X1) & 201 & 1225 & & & & 5,3 \\
\hline Koordinasi (X2) & 579,5 & 8942,011 & 780,5 & 755,69 & 1134,19 & 15,25 \\
\hline Kelincahan (X3) & 554,7 & 8164,841 & & & & 14,6 \\
\hline
\end{tabular}

Statistik di atas digunakan untuk melakukan analisis korelasi, dan untuk memperoleh koefisien validitas butir tes kebugaran jasmani untuk siswa putra sekolah dasar tetapi data yang diperoleh harus dirubah terlebih dahulu ke data Tskor karena memiliki satuan yang berbeda.

Hasil Analisis Koefisien Validitas Tes Berangkai (Battery Test) Yang Terdiri Dari Bast Test (X1) Dan Plate Taping (X2) Siswa Putra Sd Adalah 0,212. Sedangkan Hasil Analisis Koefisien Validitas Tes Berangkai (Battery Test) Yang Terdiri Dari Bast Test (X1) Dan Plate Taping (X2) Siswa Putri Sd Adalah 0,154. Hasil Analisis Koefisien Validitas Tes Berangkai (Battery Test) Yang Terdiri Dari Bast Test (X1) Dan Shuttle Run (X3) Siswa Putra Sd Adalah 0,196. Sedangkan Hasil Analisis Koefisien Validitas Tes Berangkai (Battery Test) Yang Terdiri Dari Bast Test (X1) Dan Shuttle Run (X3) Siswa Putri Sd Adalah 0,236. Hasil Analisis Koefisien Validitas Tes Berangkai (Battery Test) Yang Terdiri Dari Plate Taping (X2) Dan Shuttle Run (X3) Siswa Putra Sd Adalah 0,003. Sedangkan Hasil Analisis Koefisien Validitas Tes Berangkai (Battery Test) Yang Terdiri Dari Plate Taping (X2) Dan Shuttle Run (X3) Siswa Putri Sd Adalah 0,342. Agar Dapat Digunakan Sesuai Dengan Tujuan, Selanjutnya Koefisien Validitas Tersebut Dikonsultasikan Dengan Pendapat Kirkendal, Gruber Dan Johnson (1980) Tentang Makna Besarnya Koefisien Validitas Suatu Tes. Kualifikasi Kebermaknaan Koefisien Validitas, Kirkendal, Gruber Dan Johnson (1980) Memberikan Petunjuk Sebagai Berikut: Excellent 0,80 - 1.00; High 0,70 0,79; Average Or Fair 0,50 - 0,69; Dan Unacceptable 0,00 - 0,49.

Tabel 2. Koefisien Validitas Tes Kebugaran Jasmani Siswa Sekolah Dasar

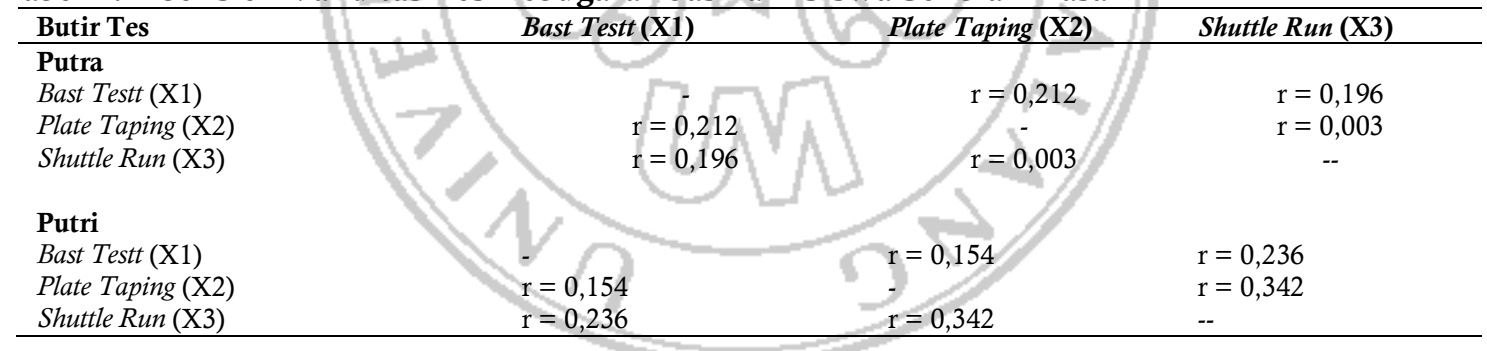

Pada tabel 4.2 di atas dapat diketahui bahwa nilai validitas X1X2 sebesar 0,212, validitas X1X3 sebesar 0,196 dan Validitas X2X3 sebesar 0,003.

Setelah Dilakukan Konsultasi Dengan Kualifikasi Kebermaknaan Koefisien Validitas Tersebut, Maka Koefisien Validitas Tes Berangkai (Battery Test) Yang Terdiri Dari Bast Test (X1) Dan Plate Taping (X2) Siswa Putra Sd Adalah 0,212, Termasuk Dalam Kategori Tidak Dapat Diterima (Unacceptable) Dan Koefisien Validitas Tes Berangkai (Battery Test) Yang Terdiri Dari Bast Test (X1) Dan Plate Taping (X2) Siswa Putri Sd Adalah 0,154, Termasuk Dalam Kategori Tidak Dapat Diterima (Unacceptable). Selanjutnya Untuk Validitas Tes Berangkai (Battery Test) Yang Terdiri Dari Bast Test (X1) Dan Shuttle Run (X3) Siswa Putra Sd Adalah 0,196, Termasuk Dalam Kategori Tidak Dapat Diterima (Unacceptable) Dan Koefisien Validitas Tes Berangkai (Battery Test) Yang Terdiri Dari Bast Test (X1) Dan Shuttle Run (X3) Siswa Putri Sd Adalah 0,236, Termasuk Dalam Kategori Tidak Dapat Diterima (Unacceptable). Selanjutnya, Koefisien Validitas Tes Berangkai (Battery Test) Yang Terdiri Dari Plate Taping (X2) Dan Shuttle Run (X3) Siswa Putra Sd Adalah 0,003, Termasuk Dalam Kategori Tidak Dapat Diterima (Unacceptable) Dan Koefisien Validitas Tes Berangkai (Battery Test) Yang Terdiri Dari Plate Taping (X2) Dan Shuttle Run (X3) Siswa Putri Sd Adalah 0342, Termasuk Dalam Kategori Tidak Dapat Diterima (Unacceptable). 
Tabel 3. Koefisien Reliabilitas Tes Kebugaran Jasmani Bast Test (X1), Plate Taping (X2), dan Shuttle Run (X3), Siswa Sekolah Dasar

\begin{tabular}{|c|c|c|c|c|c|}
\hline Kelompok & $\sum$ Total & $\sum \mathbf{X}_{1}$ & $\sum \mathbf{X}_{1}^{2}$ & $\begin{array}{l}\text { Koefsien Korelasi } \\
\text { Klp. Gj.Gn. }\end{array}$ & Koefisien Reliabilitas \\
\hline \multicolumn{6}{|l|}{ Putra } \\
\hline \multicolumn{6}{|l|}{ Bass Test (X1) } \\
\hline Ganjil & \multirow[t]{2}{*}{200} & 107 & $\begin{array}{l}735 \\
515\end{array}$ & \multirow[t]{2}{*}{0,085} & \multirow[t]{2}{*}{0,157} \\
\hline $\begin{array}{l}\text { Genap } \\
\text { Plate Taping }(X 2)\end{array}$ & & 93 & 545 & & \\
\hline Ganjil & \multirow{3}{*}{500,56} & 247,27 & 3445,40 & \multirow{3}{*}{$-0,228$} & \multirow{3}{*}{$-0,592$} \\
\hline Genap & & 253,29 & 3599 & & \\
\hline Shuttle run (X2) & & & & & \\
\hline $\begin{array}{l}\text { Ganjil } \\
\text { Genap }\end{array}$ & 473,499 & $\begin{array}{l}235,32 \\
238,18\end{array}$ & $\begin{array}{c}3087,62 \\
3188,62\end{array}$ & 0,096 & 0,175 \\
\hline \multicolumn{6}{|l|}{$\begin{array}{l}\text { Putri } \\
\text { Bass Test }(X 1)\end{array}$} \\
\hline $\begin{array}{l}\text { Ganjil } \\
\text { Genap } \\
\text { Plate Taping (X2) }\end{array}$ & 184 & $\begin{array}{ll}97 & \\
& 87\end{array}$ & ${ }^{627} 598$ & 0,419 & 0,591 \\
\hline $\begin{array}{l}\text { Ganjil } \\
\text { Genap }\end{array}$ & \multirow[t]{2}{*}{550,31} & $\begin{array}{l}284,42 \\
265,89\end{array}$ & $\begin{array}{l}4747,40 \\
4194,61\end{array}$ & \multirow[t]{2}{*}{$-0,265$} & $-0,722$ \\
\hline Shuttle run $(X 2)$ & & & & & \multirow[b]{2}{*}{0,159} \\
\hline $\begin{array}{l}\text { Ganjil } \\
\text { Genap }\end{array}$ & 527,09 & $\begin{array}{r}263,32 \\
263,77\end{array}$ & $\begin{array}{l}4091,39 \\
4073,45\end{array}$ & & \\
\hline
\end{tabular}

Hasil Analisis Koefisien Reliabilitas Tes Kebugaran Jasmani Unsur Keseimbangan (Bast Test) (X1) Untuk Siswa Putra Sekolah Dasar Yang Diperoleh Adalah 0,157. Hasil Analisis Koefisien Reliabilitas Tes Kebugaran Jasmani Unsur Koordinasi (Plate Taping) (X2) Untuk Siswa Putra Sekolah Dasar Yang Diperoleh Adalah -0,592. Tes Kebugaran Jasmani Unsur Kelincahan (Shuttle Run) (X3) Untuk Siswa Putra Sekolah Dasar Yang Diperoleh Adalah 0,175. Sedangkan Hasil Analisis Koefisien Reliabilitas Tes Kebugaran Jasmani Unsur Keseimbangan (Bast Test) (X1) Untuk Siswa Putri Sekolah Dasar Yang Diperoleh Adalah 0,591. Hasil Analisis Koefisien Reliabilitas Tes Kebugaran Jasmani Unsur Koordinasi (Plate Taping) (X2) Untuk Siswa Putri Sekolah Dasar Yang Diperoleh Adalah 0,722. Tes Kebugaran Jasmani Unsur Kelincahan (Shuttle Run) (X3) Untuk Siswa Putri Sekolah Dasar Yang Diperoleh Adalah 0,159. Selanjutnya, Koefisien Reliabilitas Tersebut Dikonsultasikan Dengan Pendapat Kirkendal, Gruber Dan Johnson (1980) Tentang Makna Besarnya Koefisien Reliabilitas Suatu Tes Agar Dapat Digunakan Sesuai Dengan Tujuan. Kualifikasi Kebermaknaan Koefisien Reliabilitas, Kirkendal, Gruber Dan Johnson (1980) Memberikan Petunjuk Sebagai Berikut: Excellent 0,90 - 1.00; High 0,80 - 0,89; Average 0,60 - 0,79; Dan Unacceptable 0,00-0,59.

Setelah Dilakukan Konsultasi Dengan Kualifikasi Kebermaknaan Koefisien Reliabilitas Tersebut Maka Tes Kebugaran Jasmani Unsur Keseimbangan (Bast Test) (X1) Untuk Siswa Putra Sekolah Dasar Yang Mempunyai Koefisien Reliabilitas 0,157 Termasuk Dalam Katagori Tidak Dapat Diterima (Unacceptable). Tes Kebugaran Jasmani Unsur Koordinasi (Plate Taping) (X2) Untuk Siswa Putra Sekolah Dasar Yang Mempunyai Koefisien Reliabilitas -0,592 Termasuk Dalam Katagori Tidak Dapat Diterima (Unacceptable). Tes Kebugaran Jasmani Unsur Kelincahan (Shuttle Run) (X3) Untuk Siswa Putra Sekolah Dasar Yang Mempunyai Koefisien Reliabilitas 0,175 Termasuk Dalam Katagori Tidak Dapat Diterima (Unacceptable).

\section{PEMBAHASAN}

\section{Pembahasan Tentang Hasil Analisis Koefisien Validitas}

Tujuan Penelitian Dan Pengembangan Ini Adalah Membuat Tes Kebugaran Jasmni Untuk Siswa Putra Dan Putri Sekolah Dasar Yang Valid Dan Reliabel. Sesuai Dengan Tujuan Penelitian Dan Pengembangan Tersebut Maka Spesifikasi Produk Yang Dihasilkan Adalah Tes Kebugaran Jasmani Yang Valid Dan Reliabel Untuk Mengukur Kebugaran Jasmani Siswa Putra Dan Putri Sekolah Dasar. Untuk Memperoleh Validitas Dan Relaiabilitas Tes Kebugaran Jasmani Tersebut Telah Dilakukan Langkah-Langkah Pengumpulan Data Dan Analisis Data.

Terdapat beberapa macam instrumen asesmen untuk kebugaran jasmani yang dapat digunakan salah satunya "Eurofit Test" yang sudah dikembangkan dibelahan benua Eropa. Tes ini telah beberapa kali diuji melalui pilot study maupun main study yang menunjukan hasil validitas yang memenuhi 
kriteria sehingga dapat menggambarkan secara jelas tentang kapasitas motorik dan kemampuan gerak dasar anak-anak maupun remaja serta dapat digunakan sebagai pemetaan, identifikasi, serta pemantauan tingkat kebugaran jasmani (Plyakov, 2017; Popović, 2017; Tomkinson et al., 2018). Instrumen ini juga memiliki tingkat validitas yang tinggi ketika hasilnya dibandingkan berdasrkan karakteristik gender dengan setiap karakteristik subjek di berbagai Negara memiliki hasil perbandingan capaian yang berbeda pada masing-masing jenis test antara siswa laki-laki dan perempuan (Apanowicz, 2018; Berisha \& Cilli, 2017; Tomkinson et al., 2019).

Pada implementasi Eurofit Test untuk anak Indonesia terdapat beberapa perbedaan yang signifikan dibandingkan dengan hasil yang didapatkan pada pelaksanaan test pada negara lain khususnya pada aspek keseimbangan, koordinasi dan kelincahan. Temuan yang didapatkan bahwa semua anak yang menjadi partisipan pada tes memiliki hasil yang cukup variatif. Berbanding terbalik dengan temuan dari (Somwhong et al., 2017) dimana semua anak yang berpartisipasi pada tes memiliki hasil yang memenuhi kriteria. Setelah dilakukan investigasi ternyata didapatkan temuan yang menarik dimana tingkat validasi hasil tes untuk anak usia sekolah dasar di Indonesia cukup rendah. Perlu identifikasi lebih lanjut terkait temuan tersebut dikarenakan negara pada asia tenggara satu rumpun memiliki karakteristik yang berbeda. Fakta teoritis dari (Emeljanovas et al., 2020; Scheuer et al., 2019) yang dapat memperkuat temuan tersebut adalah setiap subjek yang berbeda, serta kemampuan yang berbeda memerlukan pendekatan asesmen dengan tingkat validasi yang sesuai dengan konsistensi hasil yang jelas.

Faktor lain yang dapat dijadikan asumsi teoritis adalah tingkat partisipasi terhadap aktifitas fisik. Keterlibatan anak secara aktif dalam kegiatan olahraga e.g; tenis, karate, senam, dll dapat meningkatkan kapasitas fisikal dan kesegaran jasmani (Altavilla et al., 2019; Kaya et al., 2018). Factor lain yang dapat mempengaruhi kapasitas fisikal anak adalah tingkat aktifitas diam yang menetap (sedentary) yang pada saat sekarang mengalami peningkatan (Latorre-Román et al., 2016; Wyke et al., 2019). Pengenalan secara berkala terhadap jenis-jenis aktifitas tes kebugaran jasmani dapat mempengaruhi tingkat capaian hasil (Vrbik et al., 2016). Perhatian secara mendalam terhadap aktifitas anak perlu dilakukan mengingat bahwa perbedaan gender dapat mempengaruhi tingkat perbedaan kapasitas fisikal. Berdasar pada usia sekolah dasar tingkat kapasistas fisikal e.g; kelincahan, kecepatan, koordinasi keseimbangan serta indeks masa tubuh memiliki tingkat perbedaan dimana tidak selalu anak laki-laki yang memiliki tingkat kapasitas lebih tinggi (Hariadi et al., 2019; Iri et al., 2017). Pemantauan secara berkala terhadap anak menggunakan instrumen yang disarankan sangat efektif untuk meningkatkan tingkat kesegaran jasmani (Kolle et al., 2020; Leuciuc, 2017). Eurofit Test menjadi salah satu instrumen yang dapat dikenalkan sejak awal dan dapat meningkatkan kapasitas kebugaran jasmani (Kolovos et al., 2020).

\section{KESIMPULAN}

Berdasarkan hasil konsultasi tersebut, maka dapat diambil kesimpulan bahwa tes kebugaran jasmani mempunyai koefisien reliabilitas yang tidak dapat diterima. Dengan demikian, tes kebugaran jasmani tersebut tidak reliabel untuk digunakan sebagai tes dan mengukur kebugaran jasmani siswa putra dan putri Sekolah Dasar. Hal ini di karenakan tes berangkai (battery test) tersebut merupakan tes yang digunakan untuk mengukur kebugaran jasmani siswa Sekolah Dasar di daerah eropa. Berarti tes berangkai (battery test) tersebut tidak cocok digunakan untuk mengukur kebugaran jasmani siswa Sekolah Dasar yang ada didaerah Indonesia. Perlu ada studi lanjutan terkait hasil temuan tersebut yang menyebabkan terjadinya perbedaan antara anak Indonesia dengan anak di Negara yang lain.

\section{DAFTAR PUSTAKA}

Aadland, K. N., Ommundsen, Y., Aadland, E., Brønnick, K. S., Lervåg, A., Resaland, G. K., \& Moe, V. F. (2017). Executive functions do not mediate prospective relations between indices of physical activity and academic performance: The Active Smarter Kids (ASK) study. Frontiers in Psychology, 8(JUN), 1-12. https://doi.org/10.3389/fpsyg.2017.01088

Ainsworth, B., Cahalin, L., Buman, M., \& Ross, R. (2015). The Current State of Physical Activity Assessment Tools. Progress in Cardiovascular Diseases. 
https://doi.org/10.1016/j.pcad.2014.10.005

Altavilla, G., D'elia, F., D'isanto, T., \& Manna, A. (2019). Tests for the evaluation of the improvement of physical fitness and health at the secondary school. Journal of Physical Education and Sport, 19(5), 1784-1787. https://doi.org/10.7752/jpes.2019.s5262

Álvarez-Bueno, C., Pesce, C., Cavero-Redondo, I., Sánchez-López, M., Garrido-Miguel, M., \& Martínez-Vizcaíno, V. (2017). Academic Achievement and Physical Activity: A Meta-analysis. Pediatrics. https://doi.org/10.1542/peds.2017-1498

Apanowicz, M. (2018). An attempt to assess physical performance of male and female pupils who play selected musical instruments as compared to reference values of the Eurofit test battery provided by Dobosz. 8(8), 796-808.

Berisha, M., \& Cilli, M. (2017). Comparison of Eurofit Test Results of 11-17-Year- Old Male and Female Students in Kosovo. European Scientific Journal, ESJ, 13(31), 138. https://doi.org/10.19044/esj.2017.v13n31p138

Broto, G. S. D. (2014). Riset Kominfo dan UNICEF Mengenai Perilaku Anak dan Remaja Dalam Menggunakan Internet. SIARAN PERS NO. 17/PIH/KOMINFO/2/2014.

Chomitz, V. R., Slining, M. M., McGowan, R. J., Mitchell, S. E., Dawson, G. F., \& Hacker, K. A. (2009). Is there a relationship between physical fitness and academic achievement? Positive results from public school children in the Northeastern United States. Journal of School Health. https://doi.org/10.1111/j.1746-1561.2008.00371.x

Craig, C. L., Marshall, A. L., Sjöström, M., Bauman, A. E., Booth, M. L., Ainsworth, B. E., Pratt, M., Ekelund, U., Yngve, A., Sallis, J. F., \& Oja, P. (2003). International physical activity questionnaire: 12-Country reliability and validity. Medicine and Science in Sports and Exercise. https://doi.org/10.1249/01.MSS.0000078924.61453.FB

Donnelly, J. E., Hillman, C. H., Castelli, D., Etnier, J. L., Lee, S., Tomporowski, P., Lambourne, K., \& Szabo-Reed, A. N. (2016). Physical activity, fitness, cognitive function, and academic achievement in children: A systematic review. In Medicine and Science in Sports and Exercise (Vol. 48, Issue 6). https://doi.org/10.1249/MSS.0000000000000901

Emeljanovas, A., Mieziene, B., Cesnaitiene, V. J., Fjortoft, I., \& Kjønniksen, L. (2020). Physical Fitness and Anthropometric Values Among Lithuanian Primary School Children: PopulationBased Cross-Sectional Study. Journal of Strength and Conditioning Research, 34(2), 414-421. https://doi.org/10.1519/JSC.0000000000003387

Gall, M. D., Gall, J. P., \& Borg, W. R. (2003). Educational research: An introduction (7th ed.). In Boston, MA: $A \& B$ Publications.

Gall, M. D., Gall, J. P., \& Borg, W. R. (2006). Identifying a Research Problem, Question and Searching. Educational Research: An Introduction.

Haapala, E. A., Väistö, J., Lintu, N., Westgate, K., Ekelund, U., Poikkeus, A. M., Brage, S., \& Lakka, T. A. (2017). Physical activity and sedentary time in relation to academic achievement in children. Journal of Science and Medicine in Sport. https://doi.org/10.1016/j.jsams.2016.11.003

Hariadi, I., Riyad Fadhli, N., \& Sandy Yudasmara, D. (2019). Relationship Between Body Mass Index (BMI) With Agility of Elementary School Children. 7(Icssh 2018), 98-101. https://doi.org/10.2991/icssh-18.2019.23

Harvey, S. P., Lambourne, K., Greene, J. L., Gibson, C. A., Lee, J., \& Donnelly, J. E. (2018). The Effects of Physical Activity on Learning Behaviors in Elementary School Children: a Randomized Controlled Trial. Contemporary School Psychology. https://doi.org/10.1007/s40688-017-0143-0

Hills, A. P., Andersen, L. B., \& Byrne, N. M. (2011). Physical activity and obesity in children. In British Journal of Sports Medicine. https://doi.org/10.1136/bjsports-2011-090199

Howie, E. K., \& Pate, R. R. (2012). Physical activity and academic achievement in children: A historical perspective. In Journal of Sport and Health Science. 
https://doi.org/10.1016/j.jshs.2012.09.003

Ingleby, E. (2012). Research methods in education. Professional Development in Education. https://doi.org/10.1080/19415257.2011.643130

Iri, R., Aktug, Z. B., \& Ibis, S. (2017). Physical activity levels and motor skills of 5th to 7th grade students in Nigde province. South African Journal for Research in Sport, Physical Education and Recreation, 39(1), 51-64.

Jeon, Y. K., Kim, B. H., \& Kim, I. J. (2016). The diagnosis of osteoporosis. Journal of the Korean Medical Association. https://doi.org/10.5124/jkma.2016.59.11.842

Kaya, M., Saritaş, N., \& Köroğlu, Y. (2018). a Comparison of Male and Female Adolescent Tennis Players Through Selected Eurofit Test Battery. Ovidius University Annals, Series Physical Education \& Sport/Science, Movement \& Health, 18(2), 348-353. http://search.ebscohost.com/login.aspx?direct $=$ true \&db=s3h\&AN=133571278\&site=ehostlive

Kolle, E., Solberg, R. B., Grydeland, M., Säfvenbom, R., Anderssen, S. A., Ekelund, U., Berntsen, S., Resaland, G. K., Dyrstad, S., \& Steene-Johannessen, J. (2020). Evaluating the effect of increased physical activity in lower secondary school adolescents: The study protocol for the School in Motion (ScIM) study - a cluster-randomized controlled trial. Manuscript Submitted for Publication, 1-25. https://doi.org/10.21203/rs.2.20653/v1

Kolovos, S., Finch, A. P., Van Der Ploeg, H. P., Van Nassau, F., Broulikova, H. M., Baka, A., Treweek, S., Gray, C. M., Jelsma, J. G. M., Bunn, C., Roberts, G. C., Silva, M. N., Gill, J. M. R., Røynesdal, Ø., Van Mechelen, W., Andersen, E., Hunt, K., Wyke, S., \& Bosmans, J. E. (2020). Five-year cost-effectiveness analysis of the European Fans in Training (EuroFIT) physical activity intervention for men versus no intervention. International Journal of Behavioral Nutrition and Physical Activity, 17(1), 1-13. https://doi.org/10.1186/s12966-020-00934-7

Lang, J. J., Phillips, E. W., Orpana, H. M., Tremblay, M. S., Ross, R., Ortega, F. B., Silva, D. A. S., \& Tomkinson, G. R. (2018). Field-based measurement of cardiorespiratory fitness to evaluate physical activity interventions. In Bulletin of the World Health Organization. https://doi.org/10.2471/BLT.18.213728

Latorre-Román, P., Fernández-Sánchez, M., Moriana-Coronas, F.J., \& García-Pinillos, F. (2016). Design and validation of a cardiorespiratory capacity test for preschool children. South African Journal for Research in Sport, Physical Education and Recreation, 38(2), 129-137.

Leuciuc, F. V. (2017). Assessment of Students Physical Fitness by Using the Eurofit Test Battery. The Annals of "Dunarea de Jos" University of Galati. Fascicle XV, Physical Education and Sport Management, 2, 74-79. http://www.gup.ugal.ro/ugaljournals/index.php/efms/article/view/228

Mintah, J. K. (2003). Authentic assessment in physical education: Prevalence of use and perceived impact on students' self-concept, motivation, and skill achievement. Measurement in Physical Education and Exercise Science. https://doi.org/10.1207/S15327841MPEE0703_03

Mullender-Wijnsma, M. J., Hartman, E., De Greeff, J. W., Bosker, R. J., Doolaard, S., \& Visscher, C. (2015). Moderate-to-vigorous physically active academic lessons and academic engagement in children with and without a social disadvantage: A within subject experimental design Health behavior, health promotion and society. BMC Public Health. https://doi.org/10.1186/s12889015-1745-y

Plyakov, S. (2017). Eurofit Test Battery As A Methodological Basis In Establishing Unified Standards In The Field Of Physical Education And Sports. Eastern Academic Journal, 1, 1-7.

Popović, R. (2017). Evaluation of the Physical Fitness Level in Physical Education Female Students Using \&quot;Eurofit-Test\&quot; International Journal of Sports Science and Physical Education, 2(1), 1. https://doi.org/10.11648/j.ijsspe.20170201.11

Ruiz, J. R., Castro-Piñero, J., España-Romero, V., Artero, E. G., Ortega, F. B., Cuenca, M. A. M., Enez-Pavón, D. J., Chillón, P., Girela-Rejón, M. J., Mora, J., Gutiérrez, Á., Suni, J., Sjöström, 
M., \& Castillo, M. J. (2011). Field-based fitness assessment in young people: The ALPHA health-related fitness test battery for children and adolescents. British Journal of Sports Medicine. https://doi.org/10.1136/bjsm.2010.075341

Saint Albin, O. A., Fouquet, B., Doury-Panchout, F., \& Nardoux, J. (2017). Obesity and physical education: What is the link? Annals of Physical and Rehabilitation Medicine, 60, e73. https://doi.org/10.1016/j.rehab.2017.07.187

Sallis, J. F., McKenzie, T. L., Alcaraz, J. E., Kolody, B., Faucette, N., \& Hovell, M. F. (1997). The effects of a 2-year physical education program (SPARK) on physical activity and fitness in elementary school students. American Journal of Public Health. https://doi.org/10.2105/AJPH.87.8.1328

Scheuer, C., Herrmann, C., \& Bund, A. (2019). Motor tests for primary school aged children: A systematic review. Journal of Sports Sciences, 37(10), 1097-1112. https://doi.org/10.1080/02640414.2018.1544535

SOMWHONG, N., PANICH, K., \& Amornphan, A. (2017). Physical Fitness Performance As Determined By The Eurofit Test Battery In Thai. 17(1), 57-67.

Stephani, M. R., Sumarno, G., \& Wibowo, R. (2019). Early Childhood Motor Development: Descriptive study in moslem kindergarten school. 11(Icsshpe 2018),243-245. https://doi.org/10.2991/icsshpe18.2019 .69

Tomkinson, G. R., Carver, K. D., Atkinson, F., Daniell, N. D., Lewis, L. K., Fitzgerald, J. S., Lang, J. J., \& Ortega, F. B. (2018). European normative values for physical fitness in children and adolescents aged 9-17 years: Results from 2779165 Eurofit performances representing 30 countries. British Journal of Sports Medicine, 52(22), 1445-1456. https://doi.org/10.1136/bjsports-2017-098253

Tomkinson, G. R., Lang, J. J., Blanchard, J., Léger, L. A., \& Tremblay, M. S. (2019). The 20-m shuttle run: Assessment and interpretation of data in relation to youth aerobic fitness and health. Pediatric Exercise Science, 31(2), 152-163. https://doi.org/10.1123/pes.2018-0179

Tremblay, M., \& Lloyd, M. (2010). Physical Literacy Measurement - The Missing Piece. Physical \& Health Education Journal.

Tremblay, M. S., LeBlanc, A. G., Kho, M. E., Saunders, T. J., Larouche, R., Colley, R. C., Goldfield, G., \& Gorber, S. C. (2011). Systematic review of sedentary behaviour and health indicators in school-aged children and youth. In International Journal of Behavioral Nutrition and Physical Activity. https://doi.org/10.1186/1479-5868-8-98

Venetsanou, F., \& Kambas, A. (2010). Environmental Factors Affecting Preschoolers' Motor Development. Early Childhood Education Journal. https://doi.org/10.1007/s10643-009-0350-z

Vrbik, I., Sporiš, G., Štefan, L., Madić, D., Trajković, N., Valantine, I., \& Milanović, Z. (2016). The Influence of Familiarization on Physical Fitness Test Results in Primary School-aged Children\&quot; by Vrbik I et al Article Title: The Influence of Familiarization on Physical Fitness Test Results in Primary School-aged Children. Pediatric Exercise Science. https://doi.org/10.1123/pes.2016-0091

Warburton, D. E. R., Nicol, C. W., \& Bredin, S. S. D. (2006). Health benefits of physical activity: The evidence. In CMAJ. https://doi.org/10.1503/cmaj.051351

Wyke, S., Bunn, C., Andersen, E., Silva, M. N., van Nassau, F., McSkimming, P., Kolovos, S., Gill, J. M. R., Gray, C. M., Hunt, K., Anderson, A. S., Bosmans, J., Jelsma, J. G. M., Kean, S., Lemyre, N., Loudon, D. W., Macaulay, L., Maxwell, D. J., McConnachie, A., ... van der Ploeg, H. P. (2019). Erratum: Correction: The effect of a programme to improve men's sedentary time and physical activity: The European Fans in Training (EuroFIT) randomised controlled trial (PLoS medicine (2019) 162 (e1002736)). PLoS Medicine, 16(3), e1002772. https://doi.org/10.1371/journal.pmed.1002772

Zach, S., Shoval, E., \& Lidor, R. (2017). Physical education and academic achievement-literature review 1997-2015. Journal of Curriculum Studies, 49(5), 703-721. 
https://doi.org/10.1080/00220272.2016.1234649

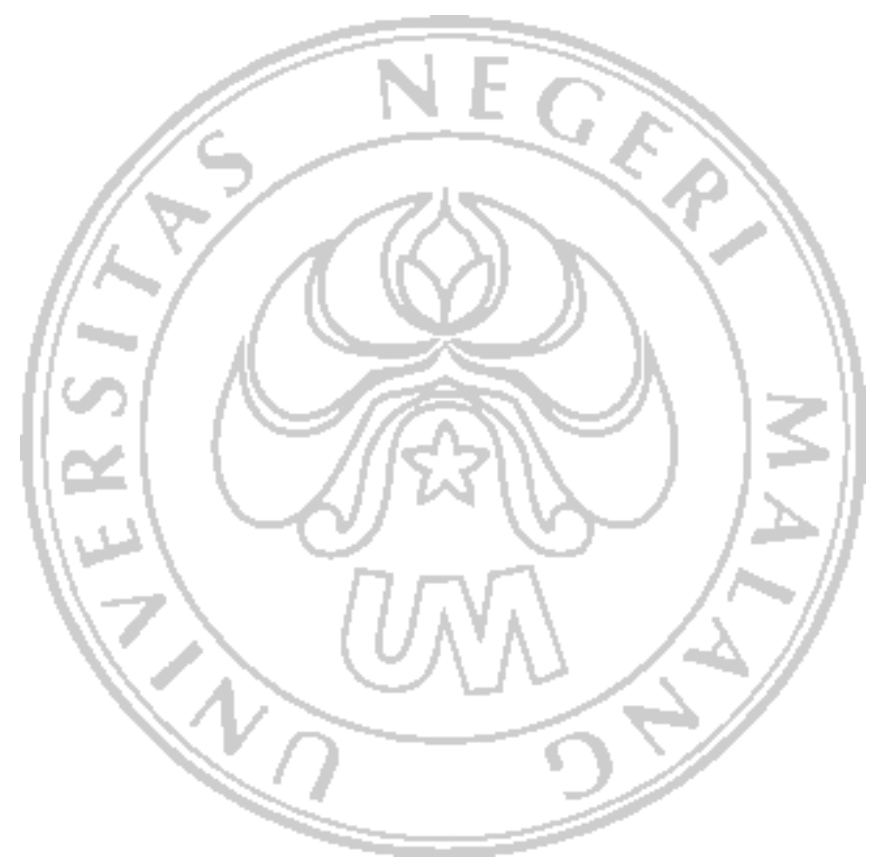

